\title{
Management of croup
}

Those who turn to the current paediatric textbooks for guidance on the management of croup may be forgiven if they are confused by what they read. Mist treatment, oxygen tents, corticosteroids, nebulised adrenaline, antibiotics, sedatives, intravenous fluids, syrup of ipecacuanha (one drop per month of age up to 2 years) ${ }^{1}$ and endotracheal intubation are advocated with enthusiasm or caution but with scant supportive evidence. Controversy about management is fuelled by serious methodological deficiencies in published studies and failure to define clearly the condition being studied. ${ }^{2}{ }^{3}$ To some authors, croup is synonymous with viral laryngotracheobronchitis, whereas others use the term to describe a symptom-complex which includes spasmodic croup, bacterial tracheitis, and acute epiglottitis, as well as laryngotracheobronchitis.

\section{Definitions}

Croup can be defined as an acute clinical syndrome with inspiratory stridor, a barking cough, hoarseness, and signs of respiratory distress due to varying degrees of laryngeal or tracheal obstruction. This definition embraces several distinct disorders with different underlying pathophysiological processes, different clinical courses, and different responses to treatment.

Acute laryngotracheobronchitis, the commonest form of croup, is most frequently caused by the parainfluenza, influenza, or respiratory syncytial viruses. The onset of barking cough, hoarseness, and stridor is usually preceded by rhinorrhoea, a sore throat, and mild fever for one or two days. The symptoms often begin, and are worse, at night but normally disappear after two to seven days. Many children have stridor with little or no respiratory difficulty but a few develop increasing tachycardia, tachypnoea, sternal and subcostal recession, and restlessness indicating severe upper airway obstruction. The intensity of the stridor, like that of wheeze in asthma, is a poor indicator of the severity of obstruction. ${ }^{4}$

Some children have repeated episodes of croup without fever or coryzal symptoms. Their symptoms are of sudden onset and at night, and often persist for only a few hours. The association of this recurrent or spasmodic croup with atopic disease and an abnormal response to inhaled histamine, suggest that hyperreactivity of the upper airway may be the underlying mechanism. ${ }^{56}$

Bacterial tracheitis, or pseudomembranous croup, is an uncommon but life threatening form of croup. ${ }^{78}$ Infection of the tracheal mucosa with Staphyloccus aureus, streptococci, or Haemophilus influenzae results in copious purulent secretions and mucosal necrosis. The child appears toxic with a high fever and the signs of progressive upper airway obstruction. The croupy cough and absence of drooling help distinguish this condition from acute epiglottitis.

Acute epiglottitis shares many of the clinical features of croup but should be regarded as a separate entity. Haemophilus influenzae B is the causative pathogen in virtually all cases, but streptococci can occasionally give a similar clinical picture. Although epiglottitis is a far less common cause of upper airway obstruction than croup, particularly in infancy, it is important because without prompt recognition and appropriate treatment there is a high risk of death. Typically the child presents with a history of a few hours of an intensely painful throat and increasing difficulty in breathing. He is unable to talk or drink and will be drooling saliva because swallowing is so painful. A high fever and pallor are present and there may be signs of poor peripheral circulation. Characteristically, the child prefers to sit upright rather than to lie down. General features of upper airway obstruction such as sternal retraction, tachycardia, and tachypnoea, are present and may worsen rapidly, particularly if the child is disturbed excessively. The stridor of epiglottitis is usually quieter and less harsh than that of croup. The absence of a croupy cough in any child with acute stridor and fever strongly suggests a diagnosis of epiglottitis.

Diphtheria, retropharyngeal abscess and laryngeal foreign body are uncommon causes of acute stridor but may be fatal if not recognised.

\section{Treatment of croup}

Accurate diagnosis, gentle handling, and careful observation are the mainstays of good management. As the distinction between viral laryngotracheobronchitis and recurrent croup, which together account for most cases of croup, is often not made in clinical practice or in published reports, the management of these two disorders will be considered 
together. The treatment of bacterial tracheitis is described separately.

The diagnosis and assessment of the severity of croup are based on the history and clinical examination. Investigations such as the white cell count and microbiological cultures rarely influence management and should not be performed as a routine. Lateral radiographs of the neck are not a reliable indicator of the severity of airway obstruction. ${ }^{9}$ The procedure is disturbing to the child and can precipitate acute obstruction and therefore should be avoided.

GENERAL SUPPORTIVE MEASURES

Children with croup are often frightened, miserable, and uncomfortable. Crying increases their oxygen demand, accelerates respiratory muscle fatigue, and may increase laryngeal swelling. Gentle confident handling helps reassure the child (and parents). Children are often more peaceful on their mother's lap than in a strange cot. Occasionally a sedative such as chloral hydrate may be needed if the child remains agitated, but drugs that can cause repiratory depression must be avoided. Nursing and medical staff must recognise that restlessness and agitation may indicate serious hypoxaemia and not simply anxiety. Adequate hydration can usually be achieved by encouraging small frequent drinks. Children with severe dyspnoea may need intravenous fluids. Nasogastric tubes cause discomfort and increase respiratory distress, and should be avoided.

\section{MIST TREATMENT}

Warm mist or water vapour is still used in the treatment of croup. In hospital, humidifiers or nebulisers are used to increase the water content of air or oxygen, which may be delivered into a plastic tent or via a face mask held a few inches from the child's mouth. Mist tents are uncomfortable and can be frightening, and they make observation more difficult. Although there is anecdotal support for the use of mist in croup, there is no objective evidence of benefit and it is unclear how mist might reduce respiratory obstruction. Bourchier and colleagues showed no significant differences over a 12 hour period in the physical signs or transcutaneous oxygen and carbon dioxide concentrations between two groups of children with viral croup, who were randomly allocated to high or normal humidity. ${ }^{10}$ The small numbers of patients (eight in each group), however, and the wide variance of most of the parameters measured, precludes a firm conclusion about this negative result. There are no other controlled studies of humidity in croup.
OXYGEN

Hypoxaemia, due to impaired alveolar ventilation and ventilation-perfusion imbalance, is common in children admitted with croup. ${ }^{11}$ The degree of hypoxaemia correlates poorly with clinical signs: the respiratory rate is the best indicator of a lowered arterial oxygen tension. Although oxygen treatment may delay the appearance of cyanosis and agitation due to hypoxia, other clinical signs such as increasing sternal retraction, tachypnoea, and tachycardia are not alleviated by oxygen and allow recognition of increasing obstruction. The measurement of oxygen saturation with pulse oximetry may be a valuable adjunct to clinical assessment. Not all croupy children admitted to hospital need oxygen but it may help those with moderate or pronounced dyspnoea. It is difficult to achieve an oxygen concentration above $40 \%$ in a tent and few children will tolerate face masks. They may, however, accept a mask which is held a short distance above their face, but the efficacy of this method of delivering oxygen is uncertain.

\section{NEBULISED ADRENALINE}

In 1971, Adair et al reported 10 years' experience of the use of racemic adrenaline delivered by intermittent positive pressure breathing in $\mathbf{5 5 0}$ children with laryngotracheobronchitis. ${ }^{12}$ (Racemic adrenaline is an equal mixture of the $\mathrm{L}$ - and $\mathrm{R}$ - isomers, but $\mathrm{L}$-adrenaline is the active component.) Adair claimed that this treatment improved airway patency and reduced or abolished the need for tracheostomy or intubation. Several small prospective controlled studies have failed to confirm Adair's retrospective observations. Although inhalation of nebulised racemic adrenaline produced improvement of clinical signs ${ }^{13-16}$ and a fall in respiratory resistance, ${ }^{14}$ these effects were shortlived (30-60 minutes) and were not associated with improvement in arterial blood gas tensions. ${ }^{13} \mathrm{~A}$ similar change occurred when adrenaline was delivered by simple nebulisation without intermittent positive pressure breathing. ${ }^{15}$ The duration of hospitalisation and the need for an artificial airway were not reduced in these studies.

Racemic adrenaline is not available in this country but adrenaline 1:1000 BP is equally effective. ${ }^{16}$ The dose of $5 \mathrm{ml}$, delivered from a nebuliser via face mask, can be repeated every two to four hours. Significant side effects have not been reported but all children receiving the drug need careful observation, preferably in an intensive care unit with continuous electrocardiographic monitoring. This form of treatment should be reserved for children with severe obstruction. Children who have no improvement or who require repeated inhalations 
are likely to require intubation. The transient improvement may be of value in the child who needs endotracheal intubation, while waiting for an experienced anaesthetist.

\section{STEROIDS}

Over the last 20 years there have been more studies to evaluate the role of corticosteroids in the management of croup than any other form of treatment. The results of these trials are confusing and conflicting because of major faults in their design. ${ }^{23}{ }^{17} \mathrm{In}$ some studies there was no distinction between viral laryngotracheobronchitis and spasmodic croup, and often no allowance for the severity of the illness. Random assignment to treatment or non-treatment groups and double blind techniques were not always employed. Different steroids have been given in different doses by different routes. Patients usually received several other treatments, such as mist or adrenaline, concurrently with steroids. There have been no agreed criteria for assessing the effects of treatment. These deficiencies make interpretation of the reported data impossible. It is difficult to justify the use of corticosteroids for a condition that almost always resolves without any specific treatment.

\section{ENDOTRACHEAL INTUBATION}

About $2-5 \%$ of children admitted with croup require an artificial airway. ${ }^{18}$ The decision to intubate is a clinical one based on increasing tachycardia, tachypnoea, and chest retraction, or the appearance of cyanosis, exhaustion, or confusion. The procedure should be performed under general anaesthetic by an experienced anaesthetist, except where there has been a respiratory arrest. If there is doubt about the diagnosis, an ear, nose, and throat surgeon capable of performing a tracheostomy should be present. Anaesthetic induction should be with oxygen and halothane through a face mask. Intravenous induction agents and relaxants should not be used. Many anaesthetists pass an orotracheal tube initially and then exchange this for a nasotracheal tube after adequate oxygenation and thorough tracheal suction have been achieved. Pulmonary oedema and pneumothorax or pneumomediastinum are uncommon complications.

Children with an endotracheal tube need meticulous observation in an intensive care unit if potentially fatal complications such as tube blockage or displacement are to be avoided. Thorough humidification of inspired gases using the humidifier of a ventilator circuit, and careful tracheal suction are essential to prevent concretion of secretions and tube blockage. Secondary infection with staphylococcus and haemophilus is common and may require appropriate antibiotics. The median duration of intubation in croup is four to five days. Nebulised adrenaline may reduce the stridor which follows extubation. ${ }^{18}$ Although tracheostomy is an equally effective way of alleviating obstruction, the morbidity and mortality are higher than with intubation. Tracheostomy should be reserved for the small minority of children where endotracheal intubation cannot be achieved, where there is recurrent tube blockage, or where prolonged intubation runs the risk of subglottic scarring.

\section{Management of bacterial tracheitis}

Early diagnosis and treatment of this potentially fatal infection are essential as the management is very different from that of other forms of croup. Four fifths of children in reported series have required intubation for severe tracheal obstruction. ${ }^{78}$ At intubation, pus aspirated from the trachea should be sent for bacterial culture. Blood cultures should also be taken, although bacteraemia is uncommon. Intravenous ampicillin and flucloxacillin should be given for seven to 10 days unless the results of bacterial culture indicate the use of other antibiotics. Even with frequent endotracheal suction and careful humidification, blockage of the endotracheal tube by crusted secretions can occur and tracheostomy may be required. There is no evidence that nebulised adrenaline or steroids are of benefit in bacterial tracheitis.

\section{Conclusions}

With the exception of antibiotics in bacterial tracheitis, there is no convincing evidence that any drug alters the natural history of croup. The brief duration of the improvement produced in some patients by nebulised adrenaline severely limits its clinical value. Steroid and mist treatment cannot be recommended on the basis of available data. Oxygen is almost certainly underused and saturation monitors may be helpful in assessing the need for oxygen.

In most children, croup is a self limiting disease requiring only considerate handling, but in a minority there is life threatening airways obstruction. Deaths from croup still occur. Some of these deaths could be avoided by more careful diagnosis of the cause of the upper airway obstruction, by earlier recognition of the clinical signs of severe obstruction and hypoxaemia, and by more prompt relief of severe obstruction by intubation. The crucial aspect of the efficient management of croup is the early recognition and alleviation of impending total respiratory obstruction. 


\section{References}

' Forfar JO. Croup. In: Forfar JO, Arneil GC, eds. Textbook of paediatrics. 3rd ed. Edinburgh: Churchill Livingstone, 1984:536-8.

${ }^{2}$ Cherry JD. The treatment of croup: continued controversy due to failure of recognition of historic, etiologic and clinical perspectives. J Pediatr 1979;94:352-4.

3 Tunnessen WW, Feinstein AR. The steroid-croup controversy: an analytical review of methodologic problems. J Pediatr 1980;96:751-6.

${ }^{4}$ Couricl JM. Acute stridor in the pre-school child. Br Med J 1984;288:1162.

5 Zach M, Erben A, Olinsky A. Croup, recurrent croup, allergy and airways hyperreactivity. Arch Dis Child 1981;56:336-41.

6 Zach M, Schnall RP, Landau LI. Upper and lower airway hyperreactivity in recurrent croup. Am Rev Respir Dis 1980;121:979-83.

7 Jones R, Santos JI, Overall JI. Bacterial tracheitis. JAMA 1979;242:721-6.

` Henry RL, Mellis CM, Benjamin B. Pseudomembranous croup. Arch Dis Child 1983;58:180-3

${ }^{9}$ Mills JL, Spackman TJ. Borns P, Mandell GA, Schwartz MW. The usefulness of lateral neck roentgenograms in laryngotracheobronchitis. Am J Dis Child 1979;133:1140-2.

10 Bourchier D, Dawson KP, Ferguson DM. Humidification in viral croup: a controlled trial. Aust Paediatr J 1984;20:289-91.
$"$ Newth CJL, Levison H, Bryan AC. The respiratory status of children with croup. J Pediatr 1972;81:1068-73.

12 Adair JC, Ring WH, Jordan WS, et al. Ten year experience with IPPB in the treatment of acute laryngotrachobronchitis. Anesth Analg 1971;50:649-55.

13 Taussig L, Castro O, Beaudry P, Fox WF, Bureau $M$. Treatment of laryngotracheobronchitis (croup): use of intermittent positive pressure breathing and racemic epinephrine. Am J Dis Child 1975;129:790-3.

${ }^{14}$ Lenney W, Milner AD. Treatment of acute viral croup. Arch Dis Child 1978;53:704-6.

${ }^{15}$ Fogel JM, Berg J, Gerber MA, Sherter CB. Racemic epinephrine in the treatment of croup: nebulisation alone versus nebulisation with IPPB. J Pediatr 1982;101:1028-31.

${ }^{16}$ Remington S, Meakin G. Nebulised adrenaline $1: 1000$ in the treatment of croup. Anaesthesia 1986;41:923-6.

17 Koren G, Frand M, Barziley Z, Macloed SM. Corticosteroid treatment of laryngotracheitis versus spasmodic croup in children. Am J Dis Child 1983;137:941-4.

18 Wagener J, Landau LI, Olinsky A, Phelan PD. Management of children hospitalised for laryngotracheobronchitis. Pediatr Pulmonol 1986;2:159-62.

J M Couriel Booth Hall Children's Hospital, Blackley, Manchester M9 2AA 